\title{
Micoplasma hyopneumoniae associado ao circovírus suíno tipo 2 em plantéis não vacinados para micoplasmose
}

\author{
Mycoplasma hyopneumoniae associated with porcine circovirus type 2 \\ in non-vaccinated herds for mycoplasmosis
}

\author{
Thales Coelho de Alvarenga ${ }^{1 *}$, Wilia Marta Elsner Diederichsen de Brito ${ }^{2,3}$, Vera Letticie de \\ Azevedo Ruiz ${ }^{4}$, Alessandra Marnie Martins Gomes de Castro ${ }^{5}$, Josete Garcia Bersano ${ }^{3}$, \\ Renato Akio Ogata ${ }^{3}$, Patrícia Soares ${ }^{2}$
}

RESUMO: A síndrome circovirose suína e doenças associadas (PCVAD) tem sido descrita em diversas regiōes do mundo. Seu agente primário, o circovírus suíno tipo 2 (PCV2), está associado a elevados índices de refugagem nas granjas e a vultuosos prejuízos econômicos. Diversos fatores de risco estão relacionados à manifestaçáo dos quadros clínicos da síndrome, nomeadamente deficiências de manejo, presença de coinfecçōes e imunizaçáo diante do agente. Entre os agentes frequentemente relatados associados ao PCV2 está o Mycoplasma hyopneumoniae. Este estudo objetivou verificar a ocorrência de $M$. hyopneumoniae em animais diagnosticados estarem acometidos pela PCVAD, em sistemas intensivos de produção de suínos do estado de Goiás. Amostras de secreção nasal de 40 animais foram analisadas para a pesquisa do DNA de $M$. hyopneumoniae. Do total das amostras de secreção nasal, 6 (15\%) foram positivas na reação em cadeia da polimerase (PCR) para o $M$. hyopneumoniae, apenas em granjas que não praticavam a vacinação contra esse agente. Os resultados relacionados à presença de micoplasma estáo de acordo com os achados clínicos dos animais analisados que apresentavam sintomatologia de doenças respiratórias e lesóes relacionadas ao trato respiratório. Este é o primeiro relato da associaçáo de PCV2 com $M$. hyopneumoniae em suínos identificados com PCVAD no estado de Goiás.

PALAVRAS-CHAVE: doenças multifatoriais; micoplasmose; síndrome circovirose suína e doenças associadas.

\begin{abstract}
Porcine circovirus associated diseases (PCVAD) have been reported around the world. They are associated with high culling rates and large economic losses. Porcine circovirus type 2 (PCV2) is the primary causative agent. Several risk factors are related to the manifestation of clinical syndrome, including deficiencies of management, presence of co-infections and immunization against involved agents. Mycoplasma hyopneumoniae is often reported as an agent associated to PCV2 infections. The aim of this study was to verify the occurrence of $M$. hyopneumoniae in animals diagnosed with PCVAD in intensive pig farming systems in Goiás, Brazil. Forty nasal secretion samples were collected for $M$. hyopneumoniae DNA detection by polymerase chain reaction (PCR). Out of this, 6 (15\%) were positive for M. hyopneumoniae DNA. All positive samples were collected from animals in non-vaccinated herds. Mycoplasma has been detected in animals showing clinical signs and lesions of respiratory diseases. To our knowledge, this is the first report of PCV2 association with $M$. hyopneumoniae in pigs with PCVAD identified in the state of Goiás, Brazil.
\end{abstract}

KEYWORDS: multifactorial diseases; mycoplasmosis; circovirus associated diseases.

\footnotetext{
'Instituto Federal Goiano - Morrinhos (GO), Brasil.

${ }^{2}$ Universidade Federal de Goiás (UFG) - Goiânia (GO), Brasil.

${ }^{3}$ Instituto Biológico - São Paulo (SP), Brasil.

${ }^{4}$ Universidade de São Paulo (USP) - Pirassununga (SP), Brasil.

${ }^{5}$ Complexo Educacional Faculdade Metropolitana Unidas - São Paulo (SP), Brasil.

*Autor correspondente: thalesvetifg@hotmail.com

Recebido em: 14/06/2016. Aceito em: 09/11/2017
} 


\section{INTRODUÇÃO}

O Brasil ocupa uma posição de destaque no âmbito do agronegócio mundial. Os baixos custos de produçáo e a melhoria nos índices zootécnicos são fatores preponderantes para a manutenção desse status. A suinocultura brasileira vem ampliando a sua participação no cenário global em razão da intensificação dos sistemas de produçáo, que conferem ao setor maior rentabilidade e acentuação da eficácia produtiva. Entretanto, os desafios sanitários continuam atuando como entraves à otimização dos resultados zootécnicos, diminuindo a competitividade do mercado brasileiro (CIACCI-ZANELLA et al., 2009).

Entre os principais desafios, a síndrome circovirose suína e doenças associadas (porcine circovirus associated diseases PCVAD) tem sido descrita em vários países (SEGALÉS et al., 2005). O seu agente primário, o circovírus suíno tipo 2 (PCV2), está relacionado ao aumento da mortalidade, diminuição do desempenho dos animais e elevados índices de refugagem, além de falhas reprodutivas em suínos (LÓPEZ-SORIA et al., 2005).

$\mathrm{Na}$ maioria dos casos clínicos, pode-se comprovar que o PCV2 é necessário, mas não exclusivo, para causar a síndrome, sendo que coinfecçóes com outros microrganismos e outros fatores, como genética, estresse, nutrição e manejo, são importantes para a manifestação do quadro clínico (ELLIS et al., 2003; PESCADOR et al., 2003; CIACCI-ZANELLA et al., 2009). Nesse cenário, os agentes que predispóem à ocorrência de síndromes associadas ao circovírus suíno devem ser considerados.

$\mathrm{O} M$. hyopneumoniae é o principal agente causador da pneumonia enzoótica suína (PES), doença caracterizada por elevada morbidade e baixa letalidade. Devido à sua patogenia, o $M$. hyopneumoniae predispóe seu hospedeiro a agentes patogênicos secundários, dentre eles o PCV2, sendo que ambos os agentes estão envolvidos no complexo de doenças respiratórias dos suínos (PRDC) (MAROIS et al., 2008).

Diante da endemicidade do PCV2 e do M. hyopneumoniae em diversas granjas produtoras de suínos no Brasil, e da escassez de estudos sobre a interaçáo entre os agentes em animais acometidos pela PCVAD, objetivou-se, neste estudo, identificar a presença do $M$. hyopneumoniae em amostras clínicas de suínos diagnosticados com circovirose em sistemas intensivos de produção de suínos no estado de Goiás.

\section{MATERIAL E MÉTODOS}

As amostras utilizadas no presente estudo foram obtidas de suínos com diagnóstico de circovirose suína de seis granjas tecnificadas de ciclo completo (SALES, 2011; SOARES, 2011) localizadas na regiáo centro sul do estado de Goiás, especificamente nos municípios de Silvânia (A), Paraúna (B), Morrinhos (C), Cristianópolis (D), Inhumas (E) e Senador Canedo (F). O estudo foi previamente submetido ao Comitê de Ética em
Pesquisa da Universidade Federal de Goiás, sendo aprovado sob o Protocolo no 259/2010.

No total, foram coletadas e analisadas amostras de secreção nasal de 40 animais, sendo 21 suínos oriundos da fase de creche, com idades entre 3 e 4 semanas; e 19 procedentes da fase de recria/terminação, com idades entre 4 e 16 semanas. Vinte animais foram eutanasiados conforme Resolução no 1.000 , de 17 de maio de 2012, do Conselho Federal de Medicina Veterinária (CFMV, 2012), e necropsiados. Foram observados aspectos macroscópicos dos linfonodos mediastínicos, mesentéricos e inguinais, do baço, dos rins, do fígado, dos pulmôes, das tonsilas e dos intestinos. Para a colheita dos espécimes clínicos, foi utilizada a metodologia descrita por SOBESTIANSKY et al. (2005).

Para a pesquisa do DNA do $M$. hyopneumoniae, foi utilizada a reaçáo em cadeia da polimerase (PCR), conforme descrito a seguir. Em microtubos, foram adicionados $500 \mu \mathrm{L}$ de soluçâo de lise (Tris-HCl pH 8,0 a 10 mM; NaCl 100 mM; EDTA 25 $\mathrm{mM}, \mathrm{pH} 8,0$; duodecil sulfato de sódio $1 \%$; e $10 \mu \mathrm{L}$ de proteinase $\mathrm{K}$ a $20 \mathrm{mg} / \mathrm{mL}$ ) a $100 \mu \mathrm{L}$ de amostra. O material foi homogeneizado e incubado a uma temperatura de $56^{\circ} \mathrm{C}$, por 2 horas. Em seguida, foram adicionados $250 \mu \mathrm{L}$ de fenol e 250 $\mu \mathrm{L}$ de clorofórmio à solução, a qual foi, na sequência, homogeneizada e centrifugada a $12.000 \mathrm{x}$ g, por 10 minutos, a $4^{\circ} \mathrm{C}$. O sobrenadante foi transferido para outro microtubo de $1,5 \mathrm{~mL}$, contendo $400 \mu \mathrm{L}$ de propanol. Após a homogeneizaçáo, as amostras foram mantidas a uma temperatura de $-20^{\circ} \mathrm{C}$, por 2 horas.

Após esse período, as amostras foram centrifugadas a $12.000 \mathrm{x} \mathrm{g}$, por 25 minutos, a $4^{\circ} \mathrm{C}$. O sedimento foi suspenso em $900 \mu \mathrm{L}$ de etanol a $70 \%$, centrifugado a $12.000 \mathrm{x}$ g por 10 minutos, a $4^{\circ} \mathrm{C}$. O sobrenadante foi descartado por inversão, e o sedimento seco, submetido a banho seco a uma temperatura de $56^{\circ} \mathrm{C}$, por 10 minutos. Por fim, o DNA foi suspenso em $30 \mu \mathrm{L}$ de solução TE $(10 \mathrm{mM}$ de Tris- $\mathrm{HCl}, 1$ $\mathrm{mM}$ de EDTA, $\mathrm{pH} 8,0$ ), e incubado em banho seco a $56^{\circ} \mathrm{C}$, por 15 minutos. As amostras com DNA extraído foram armazenadas a $-20^{\circ} \mathrm{C}$ até a sua utilização.

A amplificação do DNA de $M$. hyopneumoniae foi realizada utilizando o protocolo de ARTIUSHIN et al. (1993). Um volume de $2,5 \mu \mathrm{L}$ de DNA extraído foi adicionado a uma reação com volume final de $25 \mu \mathrm{L}$, contendo $12,5 \mu \mathrm{L}$ de DreamTaq ${ }^{\text {TM }}$ Green PCR Master Mix (2X), 0,4 $\mu \mathrm{M}$ de cada primer e água DNAse free q.s.p. Os iniciadores utilizados foram F (5'- AAGTTCATTCGCGCTAGCCC -3') e R (5'- GCTCCTACTCCATATTGCCC -3'), que amplificaram um fragmento de 483 pares de base (pb).

A reação foi realizada com aquecimento inicial da amostra em uma temperatura de $94^{\circ} \mathrm{C}$, por 10 minutos, e, na sequência, foi submetida a 39 ciclos $\left(94^{\circ} \mathrm{C}\right.$ por 30 segundos, $57^{\circ} \mathrm{C}$ por 30 segundos e $72^{\circ} \mathrm{C}$ por 60 segundos), seguida de uma extensão final a $72^{\circ} \mathrm{C}$, por 7 minutos. As amostras de secreção nasal foram testadas para o gene da $\beta$-actina, pelo método da PCR, com o intuito de descartar falso-negativo, conforme protocolo descrito por HUI et al. (2004). 
A visualizaçáo dos fragmentos amplificados foi realizada por intermédio de transiluminação do gel de agarose a 1,5\% em luz ultravioleta, após sua coloração com GelRed Nucleic Acid Gel Stain TM (Biotium, California, EUA), conforme as instruções do fabricante. Os fragmentos amplificados foram comparados a um marcador de $100 \mathrm{pb}$.

\section{RESULTADOS E DISCUSSÃO}

Do total de 40 amostras testadas pela técnica de PCR, 6 (15\%) (4G1, 7G1, 8G1, 3G4, 1G5 e 3G5) amplificaram o fragmento de M. hyopneumoniae (Figs. 1 e 2) e foram consideradas positivas no teste diagnóstico.
As seis amostras positivas eram provenientes de três das seis granjas estudadas (granja A: amostras 4G1, 7G1 e 8G1; granja D: amostra 3G4; granja E: amostras 1G5 e 3G5). Das seis amostras referidas, três eram oriundas de animais da fase de creche (amostras 4G1, 1G5 e 3G5) e as outras três provenientes de animais da fase de recria/terminaçấo (amostras 7G1, 8G1 e 3G4).

A ocorrência de coinfecçôes do PCV2 com outros agentes virais ou bacterianos é bem estabelecida e tem sido relatada em diversos estudos (CARRASCO et al., 2000; PALLARÉS et al., 2002; ALLAN et al., 2004; GRAU-ROMA et al., 2011).

Em estudo realizado nos EUA durante os anos de 2001 e 2002, 19\% dos suínos com PCVAD foram diagnosticados como coinfectados com PCV2 e M. hyopneumoniae, antecedido em número de casos apenas pelo vírus da síndrome

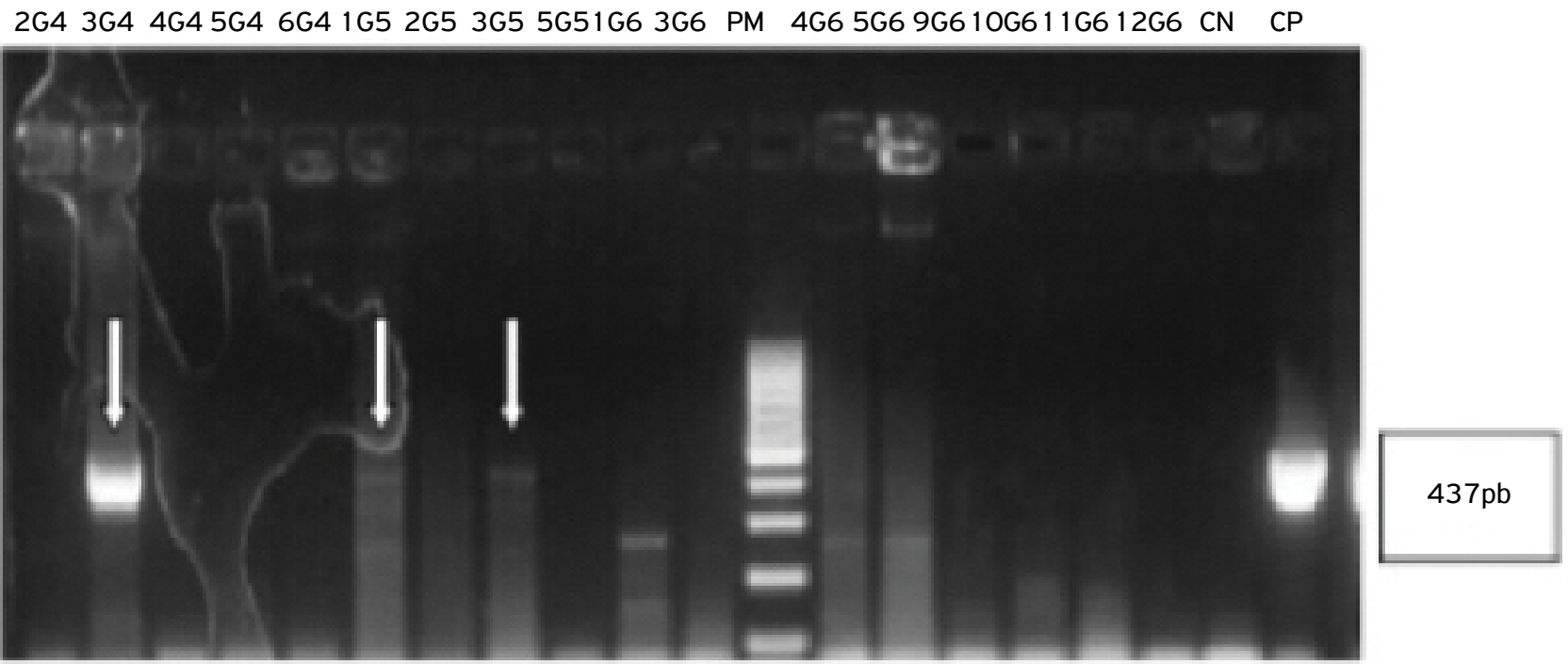

PM: peso molecular 100 pares de bases; CP: controle positivo; CN: controle negativo; $2 \mathrm{G} 4$ a 12G6: amostras de 17 animais; 3G4, 1G5, 3G5: amostras positivas.

Figura 1. Eletroforese em gel de agarose 1,5\%. Reação em cadeia da polimerase para M. hyopneumoniae a partir dos suabes nasais.

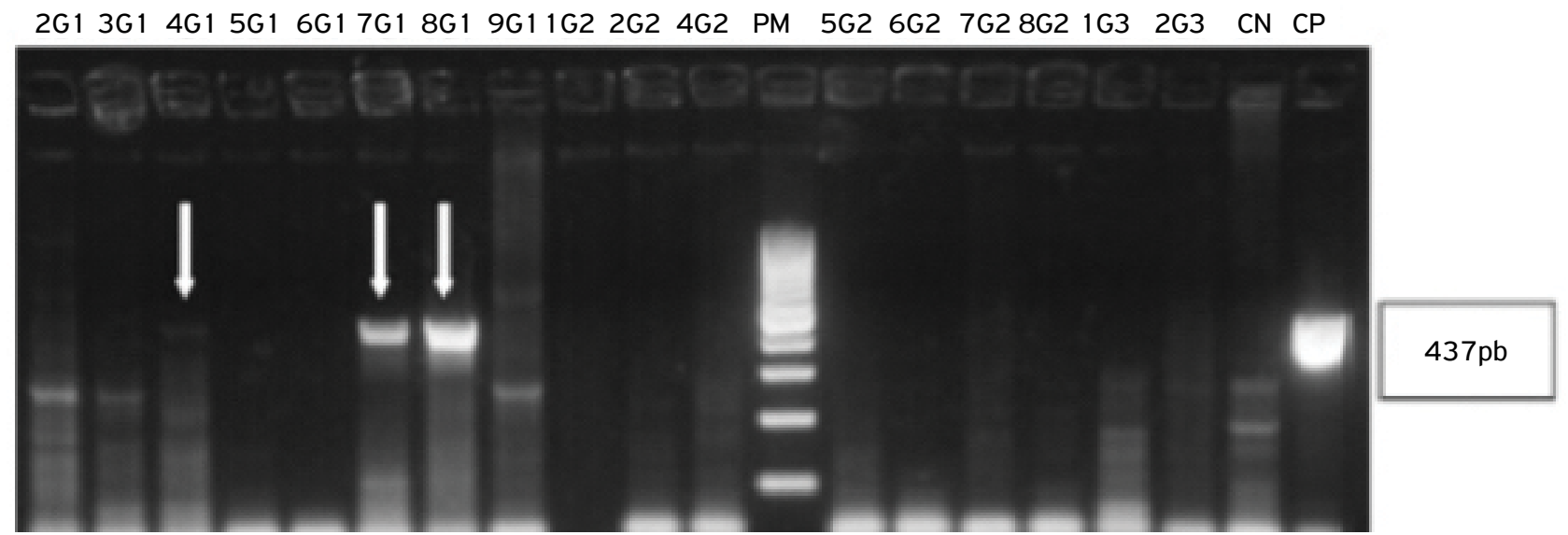

PM: peso molecular 100 pares de bases; CP: controle positivo; CN: controle negativo; $2 \mathrm{G} 1$ a 2G3: amostras de 17 animais; $4 \mathrm{G} 1$, 7G1, 8G1: amostras positivas.

Figura 2. Eletroforese em gel de agarose 1,5\%. Reação em cadeia da polimerase para M. hyopneumoniae a partir dos suabes nasais. 
reprodutiva e respiratória suína (PRRSV) (PALLARÉS et al., 2002). No Brasil, não há, ainda, notificação de doença provocada pelo PRRSV (BRASIL, 2015), nem ocorrência de anticorpos em soro de suínos, conforme estudo sorológico realizado (CIACCI-ZANELLA et al., 2013); todavia, é frequente a ocorrência de enfermidade pelo $M$. hyopneumoniae (MORÉS et al., 2015).

Apesar de a infecçáo concomitante de micoplasma com PCV2 já ter sido descrita na literatura sob as formas experimental (OPRIESSNIG et al., 2004) e mesmo de forma natural (PALLARÉS et al., 2002; MORÉS et al., 2015), até o presente momento, entretanto, ela não foi relatada no estado de Goiás.

A frequência de $15 \%$ de animais positivos para micoplasma observada neste estudo é maior do que a observada por SIBILA et al. (2008) e NATHUES et al. (2010), inferior à relatada por FONSECA JUNIOR et al. (2015) e MORÉS et al. (2015), mas semelhante à descrita por MOORKAMP et al. (2009) e VILLARREAL (2010). Diferenças nos níveis de frequência podem estar relacionadas à prevalência do micoplasma nas populaçōes suínas. De acordo com MAROIS et al. (2008), os fluidos traqueobrônquicos constituem a amostra mais adequada para identificação de micoplasma, uma vez que o $M$. hyopneumoniae ataca o epitélio ciliado do trato respiratório. Todavia, em razão da praticidade do procedimento de coleta, é mais frequentemente utilizada a colheita de secreçáo nasal por meio de suabes (PIETERS et al., 2009; VILLARREAL, 2010). Dessa forma, a frequência observada neste trabalho pode estar subestimada.

No presente estudo, seis animais analisados demonstraram a presença de DNA de $M$. hyopneumoniae. Desses seis, três eram da granja $\mathrm{A}$, clinicamente diagnosticada com surto de pneumonia enzoótica (dados não mostrados). Os outros três animais positivos eram oriundos das granjas $\mathrm{D}$ e $\mathrm{E}$. Em nenhuma dessas três granjas foi relatada a prática de vacinação para micoplasma, diferentemente das outras três granjas (B, C e F), para as quais houve registro de vacinação para o referido agente (SOARES, 2011). Dessa forma, os resultados aqui obtidos estão em conformidade com o status imunológico dos animais.

Deve ser ressaltado que a prática da vacinação para micoplamose parece constituir uma grande aliada no âmbito das medidas de proteção dos animais, não apenas em face do micoplasma, como também em relação à ocorrência de PCVAD.

Avaliando as características clínicas e patológicas dos animais utilizados no presente estudo descritas por SALES (2011) e SOARES (2011), ficou evidente a ocorrência de sinais respiratórios em elevada frequência (65\%), sobretudo nos animais provenientes das granjas A, D, E e F. Traçando um comparativo entre os resultados obtidos no presente estudo e os dados observados em ambos os trabalhos, com exceção de um animal oriundo da granja E (amostra 1G5), todos os outros cinco suínos (amostras 4G1, 7G1, 8G1,
3G4 e 3G5) apresentaram sinais respiratórios, notadamente, tosse (dados não mostrados). De acordo com OPRIESSNIG et al. (2004), a tosse é um evento clínico presente em animais experimentalmente infectados com $M$. hyopneumoniae ou, ainda, coinfectados com PCV2, mas não em animais infectados apenas com PCV2.

Além disso, entre os órgãos avaliados macroscopicamente, o pulmão foi o que mais apresentou alteraçôes no grupo dos animais analisados (SALES, 2011; SOARES, 2011). Áreas de hepatização vermelha e o não colabamento pulmonar, lesóes descritas com maior frequência em animais com infecção por $M$. hyopneumoniae do que naqueles infectados com PCV2 (MORÉS et al., 2007), foram observadas em $75 \%$ dos animais, constatação que sugere a presença do micoplasma nas granjas analisadas (SALES, 2011; SOARES, 2011). Considerando os achados de necropsia dos animais eutanasiados (dados não mostrados) e positivos para micoplasma identificados neste estudo, todos eles apresentavam as lesôes pulmonares características acima descritas.

A linfoadenopatia, outro achado macroscópico, ausente em suínos infectados somente com $M$. hyopneumoniae, mas evidente em animais contaminados apenas por PCV2 ou com infecção concomitante com micoplasma (OPRIESSNIG et al., 2004), também foi observada nos animais avaliados no presente estudo (SALES, 2011; SOARES, 2011).

As evidências clínicas e patológicas verificadas nos animais analisados são compatíveis com a presença de infecção concomitante com os agentes avaliados, tais como identificados neste estudo, de forma que aquelas evidências devem ser tomadas como indícios da presença de micoplasma em plantéis com PCVAD que não foram imunizados para esse agente.

\section{CONCLUSÕES}

Os resultados obtidos permitem sugerir que, como proposto por SOARES (2011), as enfermidades respiratórias, especialmente aquelas associadas com $M$. hyopneumoniae, podem representar as manifestações clínicas mais frequentes em suínos acometidos pela PCVAD no âmbito dos plantéis do estado de Goiás estudados.

\section{AGRADECIMENTOS}

Agradecemos às médicas veterinárias Patrícia Soares e Tatyane Penha Sales, a cessão das amostras analisadas. Também à equipe do Laboratório de Doença de Suínos do Instituto Biológico de São Paulo, pela realização de análises laboratoriais. 


\section{REFERÊNCIAS}

ALLAN, G.M.; MCNEILLY, F.; ELLIS, J.; KRAKOWKA, S.; BOTNER, A.; MCCULLOUGH, K.; NAUWYNCK, H.; KENNEDY, S.; MEEHAN, B.; CHARREYRE, C. PMWS: experimental model and co-infections. Veterinary Microbiology, Amsterdam, v.98, p. 165-168, 2004.

ARTIUSHIN, S.; STIPKOVITS, L.; MINION, F.C. Development of polymerase chain reaction primers to detect Mycoplasma hyopneumoniae. Molecular and Cellular Probes, London, v.7, p.381-385, 1993.

BRASIL. Ministério da Agricultura, Pecuária e Abastecimento. Lista de doenças de notificação obrigatória ao serviço veterinário oficial. Sistema de Informação Zoossanitária, Sanidade Animal. Brasília, 2015. Disponível em: <http:// www.agricultura.gov.br/assuntos/sanidade-animal-e-vegetal/ saude-animal/arquivos-das-publicacoes-de-saude-animal/ Listadedoencasanimaisdenotificacaoobrigatoria.pdf >. Acesso em: 9 jun. 2016.

CARRASCO, L.; SEGALES, J.; BAUTISTA, M.J.; GOMEZVILLAMANDOS, J.C.; ROSELL, C.; RUIZ-VILLAMOR, E.; SIERRA M.A. Intestinal chlamydial infection concurrent with postweaning multisystemic wasting syndrome in pigs. Veterinary Research, Paris, v. 146, n. 1, p.21-23, 2000.

CIACCI-ZANELLA, J.R.; GAVA, D.; SCHAEFER, R.; KLEIN, C.S.; SILVA, V.S.; CARON, L. No indication of porcine reproductive and respiratory syndrome virus (PRRSV) infection in Brazilian swine herds. In: SWINE CONFERENCE, Saint Paul, USA. Resumos... 2013. p. 192.

CIACCI-ZANELLA, J.R.; SIMON, N.L.; PINTO, L.S.; VIANCELLI, A.; FERNANDES, L.T.; HAYASHI, M.; DELLAGOSTIN, O.A.; ESTEVES, P.A Detection of porcine Circovirus type 2 (PCV2) variants PCV2-1 and PCV2-2 in Brazilian pig population. Research in Veterinary Science, London, v.87, p.157-160, 2009.

CONSELHO FEDERAL DE MEDICINA VETERINÁRIA (CFMV). Resolução no 1.000 , de 11 de maio de 2012. Dispõe sobre procedimentos e métodos de eutanásia em animais, e dá outras providências. Diário Oficial da União, Brasília, 17 maio 2012.

ELLIS, J.; SPINATO, M.; YONG, C.; WEST, K.; MCNEILLY, F.; MEEHAN, B.; KENNEDY, S.; CLARK, E.; KRAKOWKA, S.; ALLAN, G. Porcine Circovirus 2-associated disease in Eurasian wild boar. Journal of Veterinary Diagnostic Investigation, Columbia, v.15, p.364368, 2003.

FONSECA JUNIOR, A.A.; NONAKA, C.K.V.; GUEDES, E.O.; LOBATO, Z.I.P.; DIAS, A.S.; NASCIMENTO, J.A.F.B.; KLEIN, C.S.; REIS, J.K.P.; HEINEMANN, M.B. Detecção de agentes associados com doenças respiratórias de suínos por PCR em tempo real. Revista Brasileira de Saúde e Produção Animal, Salvador, v. 16, n.2, p.300-307, 2015.

GRAU-ROMA, L.; FRAILE, L.; SEGALÉS, J. Recent advances in the epidemiology, diagnosis and control of diseases caused by porcine circovirus type 2. The Veterinary Journal, London, v. 187 , p.23-32, 2011.
HUI, R.K.H.; ZENG, F.; CHAN, C.M.N.; YUEN, K.Y.; PEIRIS, J.S.M.; LEUNG, F.C.C. Reverse transcriptase PCR diagnostic assay for the coronavirus associated with severe acute respiratory syndrome. Journal of Clinical Microbiology, Washington, v.42, p.1994-1999, 2004.

LÓPEZ-SORIA, S.; SEGALÉS, J.; ROSE, N.; VIÑAS, M.J.; BLANCHARD, P.; MADEC, F.; JESTIN, A.; CASAL, J.; DOMINGO, M. An exploratory study on risk factors for postweaning multisystemic wasting syndrome (PMWS) in Spain. Preventive Veterinary Medicine, Amsterdam, v.69, p.97-107, 2005.

MAROIS, C.; CARIOLET, R.; MORVAN, H.; KOBISCH, M. Transmission of pathogenic respiratory bacteria to specific pathogen free pigs at slaughter. Veterinary Microbiology, Amsterdam, v.129, p.325-332, 2008.

MOORKAMP, L.; HEWICKER-TRAUTWEIN, M.; BEILAGE, E.B. Occurrence of Mycoplasma hyopneumoniae in coughing piglets (3-6 weeks of age) from 50 herds with a history of endemic respiratory disease. Transboundary and Emerging Diseases, v.56, p.54-56, 2009

MORÉS, M.A.Z.; OLIVEIRA FILHO, J.X.; REBELLATO, R.; KLEIN, C.S.; BARCELLOS, D.E.N.; COLDEBELLA, A.; MORÉS, N. Aspectos patológicos e microbiológicos das doenças respiratórias em suínos de terminação no Brasil. Pesquisa Veterinária Brasileira, Rio de Janeiro, v.35, n.8, p.725-733, 2015.

MORÉS, N.; BARCELLOS, D.; ZANELLA, J.C. Circovirose suína. In: SOBESTIANSKY, J.; BARCELLOS, D. Doenças dos Suínos. Goiânia: Cânone Editorial, 2007. 768p. p.213-226.

NATHUES, H.; KUBIAK, R.; TEGELER, R.; GROSSE BEILAGE, E. Occurrence of Mycoplasma hyopneumoniae infections in suckling and nursery pigs in a region of high pig density. Veterinary Record, London, v.13, p.194-198, 2010.

OPRIESSNIG, T.; THACKER, E.L.; YU, S.; FENAUX, M.; MENG, X.J.; HALBUR, P.G. Experimental Reproduction of Postweaning multisystemic Wasting Syndrome in Pigs by Dual Infection with Mycoplasma hyopneumoniae and Porcine Circovirus Type 2. Veterinary Pathology, Basel, v.41, p.624-640, 2004.

PALLARÉS, F.J.; HALBUR, P.G.; OPRIESSNIG, T.; SORDEN, S.D.; VILLAR, D.; JANKE, B.H.; YAEGER, M.J.; LARSON, D.J.; SCHWARTZ, K.J.; YOON, K.J.; HOFFMAN, L.J. Porcine circovirus type 2 (PCV2) coinfections in US field cases of postweaning multisystemic wasting syndrome (PMWS). Journal of Veterinary Investigation, Columbia, v.14, n.6, p.515-519, 2002.

PESCADOR, C.; ROZZA, D.B.; ZLOTOWSKI, P.; BOROWISK, S.M.; BARCELLOS, D.E.S.N.; DRIEMEIER, D. Principais lesões histológicas associadas a circovirose em suínos das fases de crescimento e terminação em rebanhos do Rio Grande do Sul. In: CONGRESSO BRASILEIRO DE VETERINÁRIOS ESPECIALISTAS EM SUÍNOS, 1 1., 2003, Goiânia. Resumos... Goiânia: ABRAVES, 2003. p.105-106. 
PIETERS, M.; PIJOAN, C.; FANO, E.; DEE, S. An assessment of the duration of Mycoplasma hyopneumoniae infection in an experimentally infected population of pigs. Veterinary Microbiology, Amsterdam, v.134, p.261-266, 2009.

SALES, T.P. Diagnóstico da circovirose suína em criações intensivas no estado de Goiás. 201 1. 54f. Dissertação (Mestrado em Ciência Animal) - Pós-graduação em Ciência Animal, Universidade Federal de Goiás, Goiânia, 2011.

SEGALÉS, J.; ALLAN, G.M.; DOMINGO, M. Porcine circovirus diseases. Animal Health Research Reviews, London, v.6, n.2, p. $119-142,2005$.

SIBILA, M.; BERNAL, R.; TORRENTS, D.; RIERA, P.; LLOPART, D.; CALSAMIGLIA, M.; SEGALÉS, J. Effect of sow vaccination against Mycoplasma hyopneumoniae on sow and piglet colonization and seroconversion, and pig lung lesions at slaughter. Veterinary Microbiology, Amsterdam, v.127, p.165-170, 2008.

SOARES, P. Identificação do circovirus suino tipo 2 e do torque teno virus em suínos de criação intensiva do Estado de Goiás. 2011.112 f. Dissertação (Mestrado em Ciência Animal) - Pósgraduação em Ciência Animal, Universidade Federal de Goiás, Goiânia, 2011.

SOBESTIANSKY, J.; BARCELLOS, D.; MORENO, A.M.; SOBESTIANSKY, A.; POLEZE, E. Suínos: coleta e remessa de material para laboratórios para fins de diagnóstico. Goiânia: Art 3, 2005. 122p.

VILLARREAL, I. Epidemiology of M. hyopneumoniae infections and effect of control measures. 2010. $221 \mathrm{f}$. Tese (Doctorado em Ciência Veterinária) - Faculdade de Medicina Veterinária, Universidade de Gante, Gante, 2010. 